\title{
Age- and sex-related differences in the spatial ecology of a dichromatic tropical python (Morelia viridis)
}

\author{
DAVID WILSON, ${ }^{1 \star}$ ROBERT HEINSOHN ${ }^{1}$ AND SARAH LEGGE ${ }^{2 \dagger}$ \\ ${ }^{1}$ Centre for Resource and Environmental Studies, Australian National University, Canberra, ACT 0200, \\ Australia (Email: davidw@cres.anu.edu.au) and ${ }^{2}$ School of Botany and Zoology, Australian National \\ University, Canberra, ACT 0200, Australia
}

\begin{abstract}
Despite outnumbering their temperate counterparts, tropical snake species have been poorly studied. Yet, the few tropical species that have been studied show a variety of behavioural traits beyond those described in temperate species. Here we reveal both age and sexual differences in the movements of tropical green pythons (Morelia viridis: Pythonidae). We radio-tracked 27 individuals (17 females and 10 males) for up to 18 months, locating individuals during both the day and night. The home range size for adult females (mean \pm SE of $6.21 \pm 1.85 \mathrm{ha}$ ) was correlated with snout-vent length. Neither adult males nor juveniles had a stable home range. Adult females had stable home ranges that overlapped considerably with those of other females and yellow individuals. Multiple radio-tracked adult males passed through the territory of radio-tracked adult females during the study. Females of all sizes were more likely to change position each day than males. There were no differences between the sexes or size categories in the distances moved in most months, although the variation in movement distances was higher in the dry season than during the wet season. In the wet season (January-March) movement distances increased and these were size- and sex-related. This increased activity may be associated with mate searching. Males of $M$. viridis may maximize their rate of encountering mature females by roaming rather than maintaining a home range. Juvenile green pythons moved distances equal to adult snakes in most months despite their comparatively small size.
\end{abstract}

Key words: home range, male mating strategy, ontogenetic colour change, sex difference, snake.

\section{INTRODUCTION}

One of the most striking differences between temperate and tropical fauna is the difference in the number of arboreal species occurring in each zone. In the tropics more than three quarters of all vertebrate species are at least partially arboreal (Kays \& Allison 2001). Within the arboreal vertebrate fauna of the tropics research is unevenly distributed across taxa, with mammals (especially primates) and birds receiving the most attention. There have been very few studies of arboreal reptiles and amphibians in tropical environments (Kays \& Allison 2001), despite the tropics containing the majority of species in these two taxa (Vitt 1987). Most major snake lineages include both tropical species and arboreal specialists (Lillywhite \& Henderson 1993). The independent evolution of arboreality in snakes from separate lineages has been accompanied by striking convergence in morphology, ecology and behaviour (Lillywhite \& Henderson

*Corresponding author.

†Present address: Australian Wildlife Conservancy, Mornington Island Sanctuary, PMB 625, Derby, West Australia 6288, Australia.

Accepted for publication December 2005.
1993), presumably reflecting similar ecological pressures. In Australia all snake families include species with arboreal and tropical representatives, with these traits most pronounced in the Australian pythons (Greer 1997). In general, arboreal species have attracted less scientific attention than their terrestrial counterparts, presumably due to logistic constraints (Bell et al. 1991). Radio-telemetry offers a solution to this problem, and can provide insights into otherwise cryptic, arboreal species (Webb \& Shine 1997a; Fitzgerald et al. 2002).

In this study we used radio-telemetry to examine the sexual and age-related differences in spatial ecology and movements of the green python (Morelia viridis: Pythonidae) - a rainforest species restricted to New Guinea and northern Cape York Peninsula, Australia (O'Shea 1996). Morelia viridis is a small ambush predator (maximum of $1.6 \mathrm{~m}$ ) and the most arboreal species in the genus Morelia (Greer 1997). Morelia viridis shows complete ontogenetic colour change with juvenile individuals changing from either yellow or red to green adults, with the change for yellow individuals occurring between 55 and $60 \mathrm{~cm}$ (Wilson et al. in press). Morelia viridis shows one of the most striking examples of ontogenetic colour change, and determining whether or not differences exist in the ecology of 
the two colours morphs is an important step in understanding the evolutionary significance of this change. The underlying reasons for ontogenetic colour change are not yet well understood, yet this phenomenon occurs in a wide range of species (Booth 1990).

Five other Morelia species occur from southern Australia to New Guinea and the east Indonesian Archipelago (Greer 1997), and range in habitat from cool temperate to tropical environments. One species of Morelia has been intensively studied (Morelia spilota; (Slip \& Shine 1988; Shine \& Fitzgerald 1996; Heard et al. 2004; Pearson et al. 2005), while preliminary studies have been undertaken on a second species (Morelia kinghorni; Fearn et al. 2005; A. Freeman pers. comm. 2005). Both species are primarily large and terrestrial (Greer 1997), with the studies done in temperate (M. spilota) or subtropical environments (M. kinghorni). These studies allow us to contrast our results from a tropical arboreal species with those from closely related, yet ecologically dissimilar species.

Here we present data that reveal unexpected sexual and age-related differences in the home range and movement patterns of $M$. viridis that may be typical of tropical, arboreal snakes. This study is important because it highlights differences with closely related, yet more temperate and terrestrial taxa. It also provides important information on juvenile snake behaviour, which is generally lacking when compared to adult behaviour of the same species.

\section{METHODS}

\section{Study site}

Our study occurred in Iron Range National Park on Cape York Peninsula, in north-eastern Australia $\left(12^{\circ} 45^{\prime} \mathrm{S}, 143^{\circ} 17^{\prime} \mathrm{E}\right)$ (Fig. 1). Within this park there is about $500 \mathrm{~km}^{2}$ of lowland tropical rainforest in a complex mosaic with eucalypt woodland and heath (Neldner \& Clarkson 1995). Mean annual rainfall for the park is $2123 \mathrm{~mm}$ (Bureau of Meteorology 195799 average) with most rain falling during a distinct 'wet' season from December to April.

\section{Radio-tracking}

Individual pythons were found by spotlighting, and surgically implanted with radio-transmitters (models SB-2 and BD-2G - Holohil Pty Ltd, Carp, Canada) by a veterinary surgeon (Peter Barrett - Marlin Coast Veterinary Clinic) following the procedure of Webb and Shine (1997b). Transmitters weighed $5 \mathrm{~g}$ (SB-2) or $1.85 \mathrm{~g}$ (BD-2G) for green and yellow individuals, respectively, and were always $<5 \%$ of body mass for any individual $(2.3-4.4 \%$ and $0.8-5.0 \%$ of body mass for yellow and green individuals, respectively). All individuals were released at their point of capture within $72 \mathrm{~h}$. We located individuals with an ICOM-R10 receiver and Yagi 3-stage antennae (Biotelemetry Pty Ltd, Adelaide, Australia). Individuals were located up to twice each $24 \mathrm{~h}$ for the period November 2002 to April 2004. All radio-tracking was done in semi-deciduous vine forest or adjacent transitional vegetation (sensu Neldner \& Clarkson 1995). Individual pythons are typically active for short periods - between 18.00 and 20.00 hours when they move from their day resting sight to their ambush site, and between 4.00 and 8.00 hours when they return to a resting posture (Wilson et al. in press). Active individuals were never observed outside these times, and no individuals changed their resting site during the day, nor hunted at more than one location in a single night. Hence, consecutive fixes of an individual were always separated by a potential activity and location change. The order in which animals were tracked both within and among days was changed to avoid temporal autocorrelation in the data (Harris et al. 1990). Each location was marked with flagging tape and its position recorded with either a Global Positioning System (12XL; Garmin Ltd, Kansas City, USA), or by using the distance and bearing from either previous locations or prominent landmarks. Due to their arboreal nature, individuals were often concealed from our view, either by foliage or because they were too high to be observed, when we estimated its location. If a new location for a concealed individual was within $1 \mathrm{~m}$ of the previous location we considered that it had not moved.

In this paper we used the two colour categories yellow and green to define different groups of $M$. viridis. It should be noted that being green does not necessarily represent maturity (Shine \& Slip 1990); however, there was no size overlap between the colour morphs with the smallest green individual being larger and older than the largest yellow individual (Wilson et al. in press).

\section{Data analysis}

The presence or absence of a home range was determined with incremental area analysis using the $95 \%$ isopleths of the minimum convex polygon with a harmonic mean peel centre. We considered that an individual had a home range if the incremental area plot reached a plateau of at least $80 \%$ of final home range area (Rose 1982; Stone \& Baird 2002), and we used the beginning of the plateau as the minimum number of fixes required to establish the home range. Visual examination of the data showed that individuals did not repeatedly use 'core' activity areas (sensu Harris et al. 1990) so the total home range of each individual was calculated using $100 \%$ minimum convex poly- 


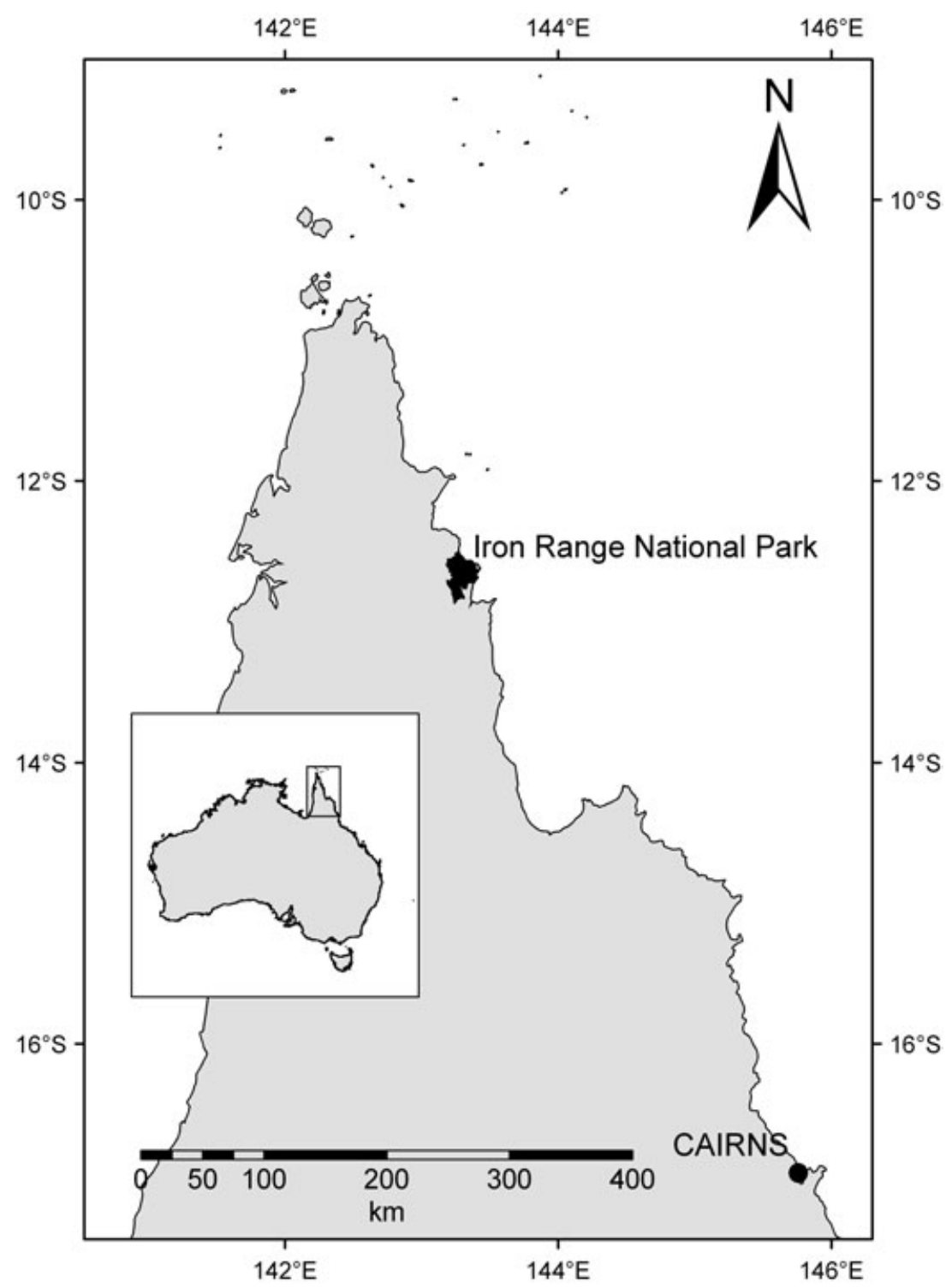

Fig. 1. Map showing the location of the study area in northern Australia.

gons. All home range analysis was done using the RANGES 6 computer program (Kenward et al. 2003). The relationships between home range size, snoutvent length (SVL), month and sex were examined using a generalized linear modelling approach. In all cases residuals were examined to confirm that data were normally distributed, otherwise data were transformed to achieve normal distributions. As data from green males did not suggest a home range, we generated a sequential movement path. Home range overlap between pairs of green female $M$. viridis was determined using the $100 \%$ minimum convex polygons, while visual comparison between green male movement paths and green female home ranges was used to determine overlap between the sexes. Figures and movement paths were generated in ArcView GIS
Version 3.1 (Esri, Redland, USA) with the Animal Movement Extension (Hooge et al. 1999).

We based the movement analysis on consecutive day fixes only, as longer intervals between fixes may underestimate daily movements. Consecutive fixes may also underestimate movement distances if individuals return to the same resting site after a period of movement. We observed green pythons re-using particular sites; however, movements between these fixes were only in the vertical plane (descending to the ground and returning). Within our study, individuals never returned to a specific location after using a new site. As our data entailed repeated measures of individual snakes we avoided pseudo-replication by fitting generalized linear mixed models incorporating the random factor 'individual' in addition to the fixed variates and 
factors of interest. In all models both 'season' and 'year' were colinear with 'month', therefore only 'month' was included in analyses.

We analysed movement in two ways. First, we analysed movement distances. Variables of interest in both analyses were SVL, the month and sex of the snake. All variables were removed sequentially from a fully factorial design to determine their significance. Movement distance was analysed with a linear mixed model, testing for the effects of SVL, month and sex. As the residuals were not normally distributed, distances were transformed using natural logarithms to obtain a better fit to the data.

Second, we examined whether or not an individual stayed in the same location between consecutive records (movement frequency). Movement frequency was analysed by defining the number of observations per month in which the snake moved as a proportion of the total observations. This was used as the response variable in a generalized linear mixed model with a binomial error distribution and logit link function. All analyses were carried out in Genstat 7 (GenstatCommittee 2003).

\section{RESULTS}

Between November 2002 and April 2004 we recorded 2178 fixes from 27 pythons (nine green and one yellow male, 12 green and five yellow females, Table 1). This period encompassed two wet seasons and the intervening dry season. Individuals were tracked for a mean of 143 days (range 15-449), with a mean of 80 fixes (range 9-251) per individual. Three individuals were monitored for the whole study, while all others were monitored for at least a single wet season. We did not detect any female reproductive activity (egg formation or laying) during the study. We report home range and movement results in two dimensions only, despite $M$. viridis being arboreal and operating in a threedimensional space. During radio-tracking we rarely recorded individuals close to the ground during the day, and often they were too high to observe and determine vertical position. Our unpublished observations show that individuals use all vegetation strata from the ground to the canopy; however, this is not represented in the data. Similarly the movement distances were reported as if locations were on the same plane, rather than in three-dimensional space. As we have no information on the relative heights at each location, true distances cannot be calculated.

\section{Home range}

An incremental area plot will plateau when enough fixes have been reached to establish a home range
(Kenward et al. 2003). For green females this plateau was reached after approximately 60 fixes (Fig. 2b). However, it was not reached in green males or yellow individuals (Fig. 2a,c), suggesting that neither group has a stable home range. The male plot appeared to plateau after 60 fixes, but only at $50 \%$ of the total home range, less than the $80 \%$ suggested by Rose (1982) and Stone and Baird (2002) to indicate a home range. One green female with insufficient fixes to reach a home range plateau was excluded from further analyses. Green female home range was $6.21 \pm 1.85$ ha (mean \pm SE). This was significantly correlated with SVL $\left(F_{1,10}=6.46, P=0.029\right)$.

There was considerable overlap in the home ranges of green females with the movement paths of green males and yellow individuals (Fig. 3). Radio-tracked green females used a combined total area of approximately 100 ha. Of 10 pairs of radio-tracked green females whose home ranges overlapped, each shared $25 \pm 11 \%$ (mean $\pm \mathrm{SE}$ ) of its total home range. Of two green females that we radio-tracked for long periods, one showed $82 \%$ home range overlap, while the other's home range was $100 \%$ within another female's home range. We also found other untracked green females within the home ranges of radio-tracked individuals suggesting that the home range overlap reported here is an underestimate. When a radio-tracked green female had a yellow individual within its territory, the green female encompassed $66 \% \pm 16 \%$ (mean \pm SE, range 17-100\%) of the yellow individual's activity areas. During the tracking period $3.3 \pm 0.5$ (mean \pm SE, range 2-4) radio-tracked green males passed through a green females' territory. We caught other green males within the home range of green females and therefore the number of males passing through a female's home range reported here is also an underestimate.

\section{Movement}

\section{Movement distance}

The distance travelled between fixes by an individual was significantly affected by a three-way interaction between sex, month and SVL (Table 2) For most months there were no differences in movement distances between individuals; however, this was not always the case for different month/sex combinations. During the wet season larger females moved further in February than in other months (Fig. 4a), while larger males moved further in January and March (Fig. 4b). During the dry season movement distances varied more between individuals than during the wet (compare the error bars in Fig. 4c,d with those in Fig. 4a,b, respectively). Distances moved for all individuals in most months varied from 3 to $23 \mathrm{~m}$ per 


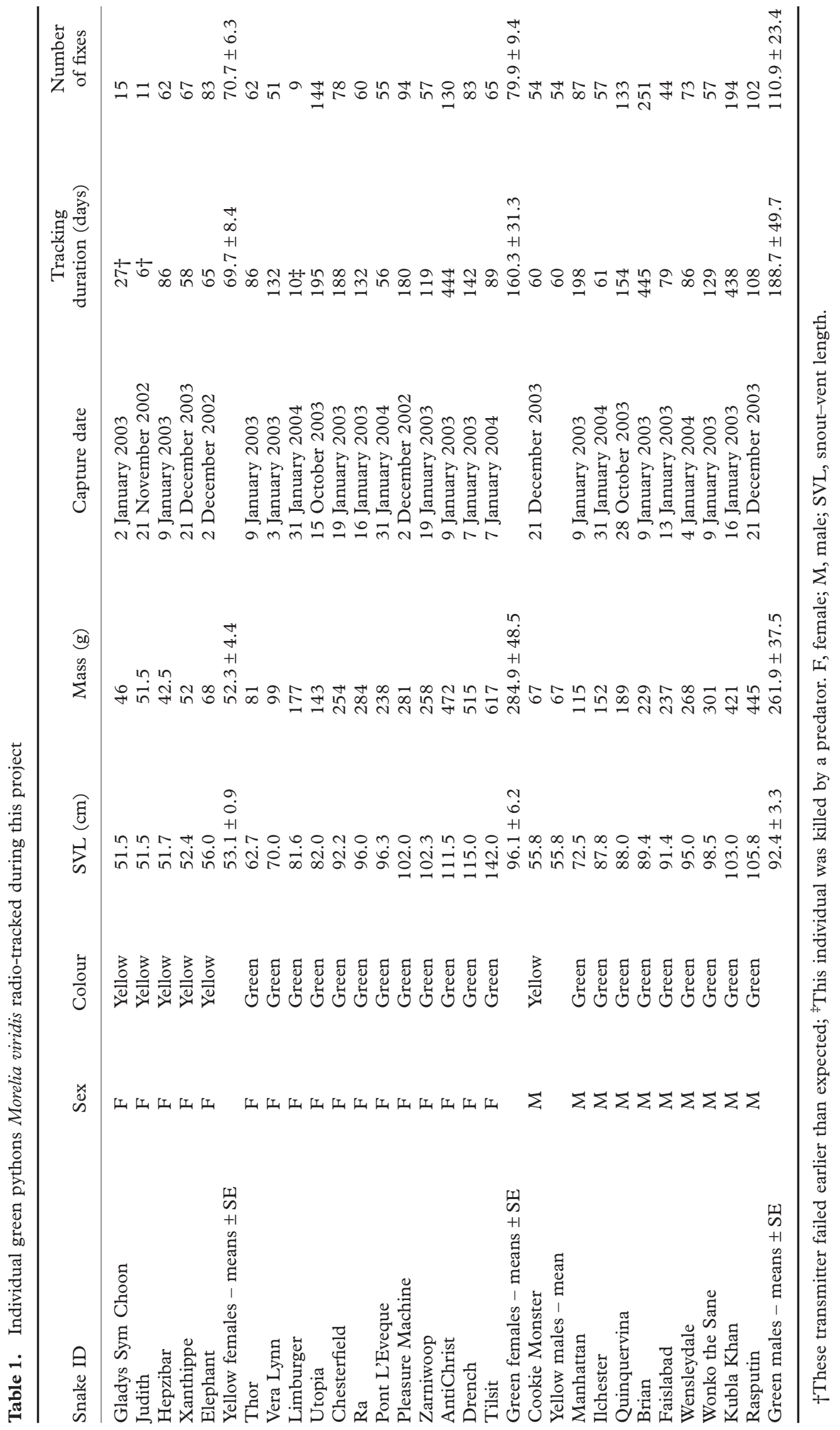



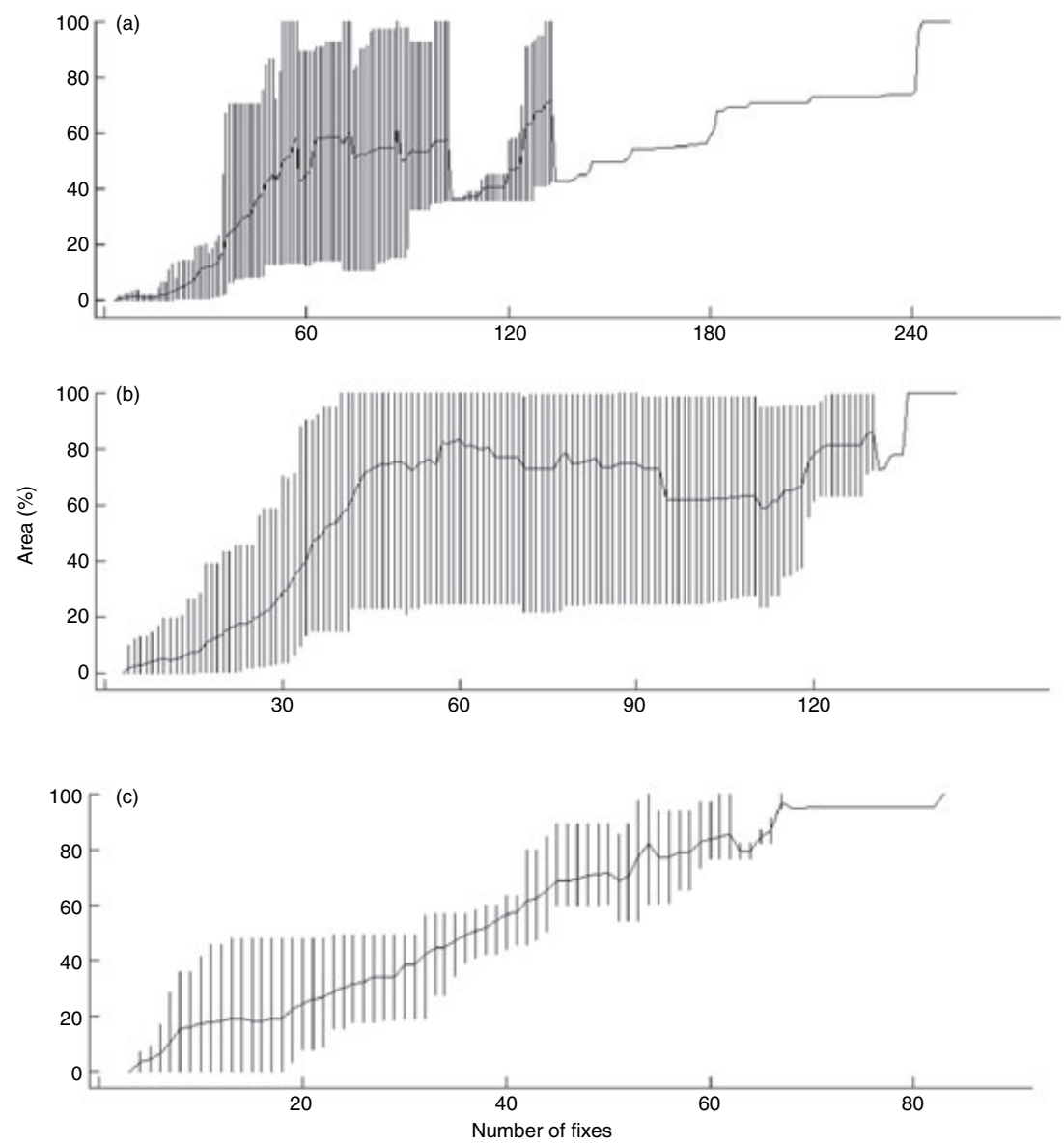

Fig. 2. Incremental area plots for Morelia viridis home ranges: (a) green males, (b) green females, and (c) yellow individuals. These analyses exclude individuals with less than 20 locations. Note the three graphs have different scales for the $x$-axes, due to differences in transmitter life between groups. The solid line represents the mean home range area as a percentage of final home range for all individuals, while the vertical lines are the $95 \%$ confidence intervals associated with the mean at each fix.

Table 2. Results for the Generalized Linear Mixed Model testing movement distances of individual Morelia viridis

\begin{tabular}{lrcr}
\hline Effect & $X^{2}$ & d.f. & $P$-value \\
\hline SVL & 14.28 & 1 & $<0.001$ \\
Month & 12.85 & 9 & 0.169 \\
Sex & 0.40 & 1 & 0.525 \\
SVL $\times$ month & 6.01 & 9 & 0.739 \\
SVL $\times$ sex & 0.09 & 1 & 0.766 \\
Month $\times$ sex & 30.91 & 8 & $<0.001$ \\
SVL $\times$ month $\times$ sex & 29.95 & 7 & $<0.001$ \\
\hline
\end{tabular}

Terms were added sequentially to the fixed model. SVL, snout-vent length.

move (values back transformed from predicted means). In January, February and March, however, the average maximum distance moved increased to approximately $50 \mathrm{~m}$. The data were highly skewed, with only eight of 1057 consecutive movement records being greater than $100 \mathrm{~m}$, while there were 753 records of movement less than $10 \mathrm{~m}$. There were 377 records of no movement between consecutive daily locations. When individuals moved resting locations, it was typically far enough away for the move to be detectable. This avoided the potential confounding effects when individuals were not sighted of detecting a movement when there was none, or not detecting a true movement. The furthest recorded move in a single night was $182 \mathrm{~m}$ for a male, and $180 \mathrm{~m}$ for a female. Individuals often hunted on a series of consecutive nights in exactly the same location, before moving to a new location. One male spent 28 days in the canopy of a single Bamaga Satinash (Syzigium bamagense) during the tree's flowering period. Other individuals spent extended periods of time in a single tree. The typical movement pattern for $M$. viridis was a sequence of 24 days of movement alternating with a few sedentary days (Table 3). Although not analysed statistically this trend was more obvious in larger individuals, and seemed to occur more during the wet than the dry season. 
(a)

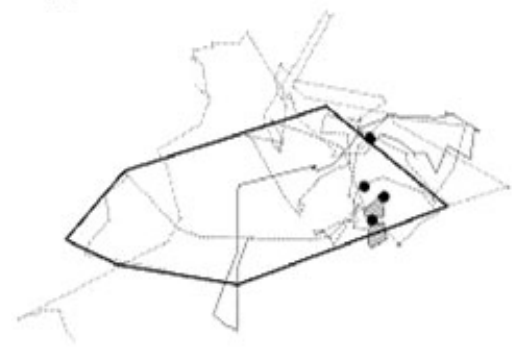

(c)

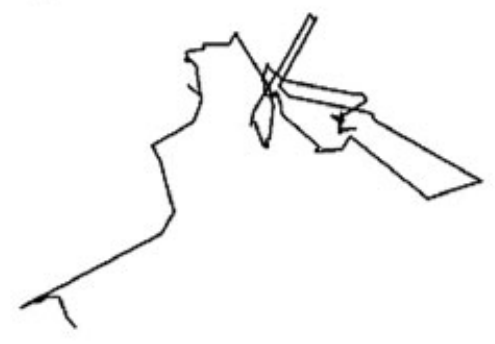

(b)

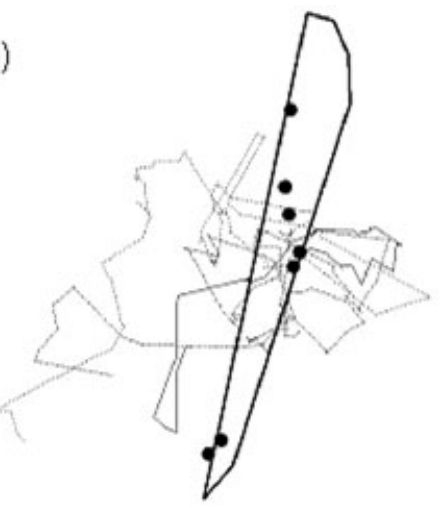

(d)

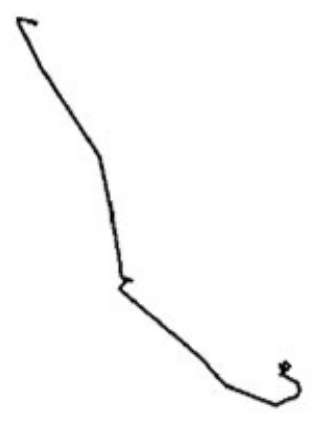

Fig. 3. Home range areas of radio-tracked green females: (a) Tilsit, and (b) Drench (enclosed polygon). Also shown are the movement paths of three green males (thin lines), activity areas of two yellow individuals (shaded polygons) and other individuals (dots) found in their home ranges during the radio-tracking period. Movement paths of two green males: (c) Kubla Khan, and (d) Ilchester.
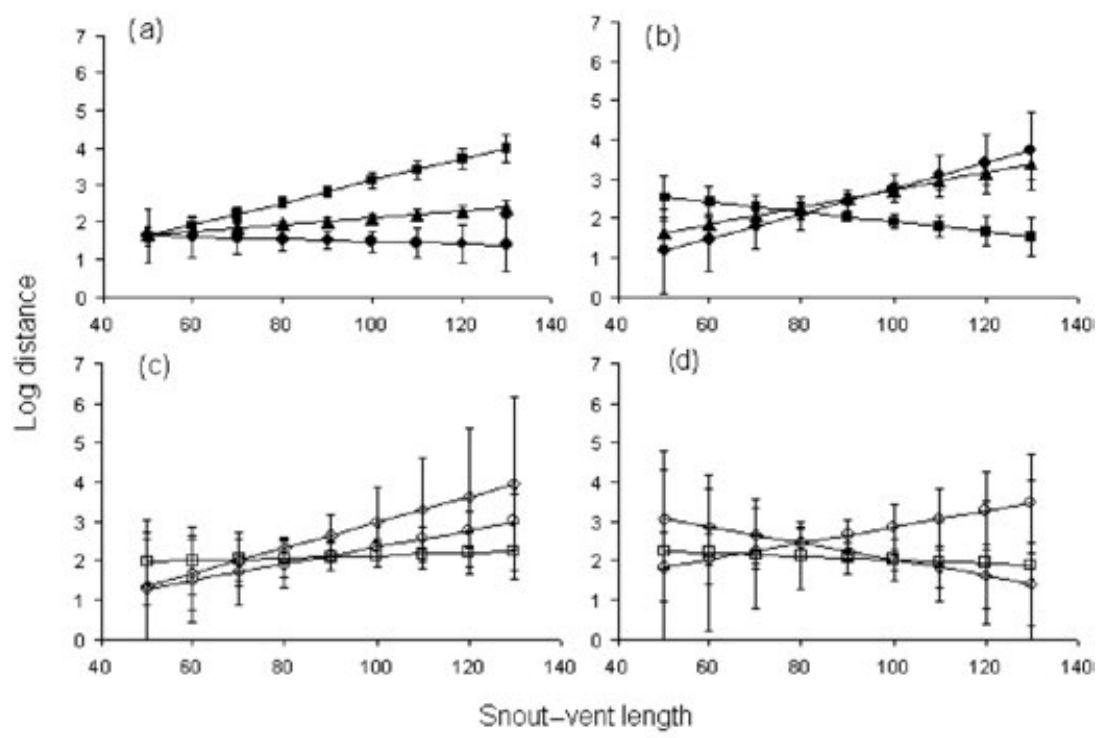

Fig. 4. Predictions of the natural logarithm of distance moved generated by Genstat for individual snakes at various times of the year. Predictions reflect the significant interaction between $x, y$ and $z$. (a) Females, and (b) males during the wet season. The three lines represent January $(\mathbf{\Delta})$, February $(\mathbf{\square})$ and March (O); (c) females, and (d) males during the dry season. The three lines represent the months of May $(\bigcirc)$, September $(\square)$, and November $(\diamond)$. Standard errors are shown. 
Table 3. Selected daily movement sequences for four Morelia viridis at Iron Range National Park

\begin{tabular}{lc}
\hline Individual & Movement distances (m) \\
\hline Antichrist (female) & $0,0,70,56,16,3,5 / / 0,0,60$, \\
& $21,0,0$ \\
Brian (male) & $0,0,94,21,42,0,0 / / 0,0,42$, \\
& $28,85,0,0$ \\
Kubla Khan (male) & $0,0,8,142,0,0 / / 0,11,39,28$, \\
& $28,3,5$ \\
Pont L'Eveque (female) & $0,32,39,2,0,0 / / 0,7,2,9,65$, \\
& $25,3,0$ \\
\hline
\end{tabular}

Movement frequency

Females were significantly more likely to move between consecutive days (proportion of consecutive records where no movement occurred, females 0.31 , males $\left.0.45, X^{2}{ }_{1}=5.47, P=0.019\right)$. This probability was independent of both the size of the individual $\left(X^{2}{ }_{1}=0.49, P=0.520\right)$ and the month $\left(X^{2}{ }_{8}=12.68\right.$, $P=0.123)$

\section{DISCUSSION}

Our study is one of the few to provide home range data for a tropical, arboreal snake. The data revealed two notable aspects of the ecology of $M$. viridis that may have broader implications for snakes in general. First, the two sexes of $M$. viridis adopt different movement strategies, with green females having a home range and males 'roaming' across the landscape. This applied to all adult males, rather than a small subset of individuals. This sexually divergent strategy has not been reported previously for either of the other intensively studied Morelia species (Slip \& Shine 1988; Fearn et al. 2005), and has not been conclusively shown in any other snake species (Parker \& Plummer 1987). Second, our data contributed detailed information on the movement patterns of juvenile snakes, which are unknown for most species. Yellow $M$. viridis moved as often as green individuals, and for comparable distances most of the year, despite being considerably smaller. They also lacked a home range, presumably as they were dispersing from their hatching site.

\section{Home range}

We used the criteria that defined a home range to exist when an incremental area plot plateaux at greater than $80 \%$ of the range area asymptote (Rose 1982; Stone $\&$ Baird 2002). We found that green females did have a home range, while both green males and yellow individuals did not. The average green female home range size of 6.21 ha is well within the range of home range sizes reported for other snake species (Macartney et al. 1988). The home range for female $M$. viridis is considerably smaller than the home range reported from the closely related M. spilota where females had a mean home range of between 11 and 37 ha (Slip \& Shine 1988; Shine \& Fitzgerald 1996). This difference is not unexpected as M. spilota are typically much larger as adults (Shine \& Slip 1990) and use a correspondingly larger area (Jetz et al. 2004).

The apparent absence of a male home range in $M$. viridis is in contrast to findings for most snakes, and specifically the other two studied Morelia species. Due to the number and duration of individual males radio-tracked we believe this result to be a true indication of their movement pattern, rather than an artefact of small sample size or limited tracking duration.

Males of both M. spilota and M. kinghorni appear to have established home ranges (Slip \& Shine 1988; Fearn et al. 2005; Pearson et al. 2005). The comparison between male movement patterns in $M$. viridis and M. kinghorni is particularly interesting. Both species occur in the tropics; however, $M$. kinghorni reaches far greater sizes, is more often active during the day and is not as arboreal as M. viridis (Greer 1997; Fearn et al. 2005).

In a review of snake home ranges Macartney et al. (1988) found that all studies reported home ranges for all categories examined (either males and females separately, or both sexes together). Since that review, one study on water pythons Liasis fuscus in Australia has reported the absence of home range (Madsen $\&$ Shine 1996). For this species neither sex had a stable home range, which the authors attributed to seasonably variable prey abundances. The main prey for $M$. viridis at Iron Range (Rattus leucopus and Melomys capensis) occur at high densities year-round (Leung 1999a,b) so variable prey density is unlikely to explain the lack of a home range in males.

Our data suggest that green $M$. viridis males may be conforming to a 'roaming' strategy (Sandell \& Liberg 1992), which predicts that under some combination of conditions males may have a greater reproductive benefit by not maintaining a home range. Specifically, they predict that roaming is favoured when males have a high search efficiency, there is a low sex ratio in the population, females have a long receptive period and there is a low level of male-male combat (Sandell \& Liberg 1992). This male strategy may also occur in the snake Nerodia sipedon. Brown and Weatherhead (1999) found that male home range size increased with tracking duration and were smaller where there were greater densities of females.

As territorial defence is rare in snakes (Gregory et al. 1987), the overlap between the home range and movement paths of individual $M$. viridis was not surprising. Individuals of many snake species display widely over- 
lapping home ranges (Gregory et al. 1987; Webb \& Shine 1997a); however, few studies have quantified this overlap (Macartney et al. 1988). Despite the high overlap we never recorded interactions between monitored individuals, and only once did we record two individuals within $5 \mathrm{~m}$ of one another.

\section{Movement}

In most months there were no differences in movement distances between the sexes, nor for individuals of different lengths. During the wet season (January, February and March), however, movement distances were affected by the size and sex of the individual, with larger individuals moving considerably further between consecutive locations than smaller individuals. We suggest seasonal differences in movements relate to mate searching. Although we did not detect any reproductive activity (enlarged ovaries or egg laying) during the study, other studies have reported increased movements during the breeding season (Madsen 1984; Brown \& Weatherhead 1999; Brito 2003). Females have also been shown to increase their movements to reach oviposition sites (Madsen 1984), although none of our radio-tracked individuals was detected to have laid eggs.

During the dry season there was considerable variation in movement distances between individuals. Although green pythons are active year round some individuals may be reducing their activity in the dry season. This contrasts with the behaviour of the water python L.fuscus in tropical Australia which was encountered much more frequently in the dry than the wet season (Brown et al. 2002).

Movement distances recorded for $M$. viridis were similar to those reported for M. spilota in temperate Australia, and interestingly both studies reported longer movements in the spring and summer (Slip \& Shine 1988; Shine \& Fitzgerald 1996). In both studies on $M$. spilota increased movements in spring and summer were in part attributed to warmer environmental conditions in addition to mate searching (Slip \& Shine 1988; Shine \& Fitzgerald 1996). Our results are also comparable with those of other ambush predators (Slip \& Shine 1988; Brito 2003; Diffendorfer et al. 2005), but markedly less than daily movement distances for active foragers (Macartney et al. 1988). The regular movement sequence we recorded for $M$. viridis has also been reported for Vipera latastei by Brito (2003), who observed this pattern of movement only during the mating season. Although the mating period of $M$. viridis is unknown, we recorded this movement pattern more often in the wet season, supporting our suggestion of mate searching during this time.

We can offer no obvious reason why females move more often than males, and no other study has reported a similar result (Diffendorfer et al. 2005), although intersexual differences in movement frequency are rarely tested in snakes (Macartney et al. 1988).

\section{Yellow versus green}

There is very little information comparing juvenile and adult snakes of the same species, mainly because their cryptic nature and size limit the methods available to study them. Our study is one of the few to radio-track juvenile snakes. We found no evidence of a home range for yellow $M$. viridis, supporting the hypothesis that juveniles are the main dispersal phase for most snakes (Greenwood 1980). Movement rates for yellow $M$. viridis were equal to those of green individuals of both sexes for most months, despite potentially large size differences (up to a threefold difference in length). Webb and Shine (1997a) also found equal movement distances between juveniles and adults in the snake Hoplocephalus bungaroides. In contrast, movement distances increased with age for M. spilota (Pearson et al. 2005).

All yellow individuals in this study were found in edge habitats or in canopy gaps created by treefalls and never inside the closed-canopy rainforest. Although we found that yellow individuals moved the same distances as adults, their movements were probably restricted to these edge habitats. One individual that changed from yellow to green during radiotracking only moved into the closed-canopy rainforest when it turned green. Although we are yet to understand the evolutionary significance of ontogenetic colour change in $M$. viridis, differential habitat use such as that reported here may prove important. In other species ontogenetic colour change has been closely linked with camouflage from both prey and predators (Booth 1990).

\section{CONCLUSION}

Our study has yielded rare data on the movement patterns of a tropical, arboreal snake species, and revealed contrasts with more terrestrial and temperate species. We found sexual differences in ranging behaviour. Adult females have a home range, whereas males adopt a 'roaming' strategy probably in search of mates. Although reported in other vertebrate taxa (Sandell \& Liberg 1992; Magnusson \& Kasuya 1997), we know of no other snake species with this dichotomous movement strategy (Parker \& Plummer 1987). Juveniles moved distances comparable to adults in most months despite large size differences, but occurred in rainforest edge habitat rather than with the closed-canopy rainforest. Future studies are required on tropical and 
arboreal snake species to determine whether the sexand age-related patterns shown for M. viridis are typical of tropical or arboreal species. The evolutionary significance of ontogenetic colour change also requires further investigation.

\section{ACKNOWLEDGEMENTS}

We thank Peter Barrett and the Marlin Coast Veterinarian Clinic for the surgery and Peter and Emma Huybers for logistical support. Andrea Cook and Karl Goetze refined the radio-tracking methods for M. viridis, based on helpful advice from Andrew Krockenberger and Jonathon Webb. Ellie Sobey, Karl Hillyard, Steve Murphy, Bess Schenk and Kristie Wilson helped in the field. Wendy Telfer and Mark Hutchinson greatly improved an earlier draft of this manuscript. This research was funded by grants from Australian Geographic, the Hermon Slade Foundation and the National Geographic Society. Research was carried out under the Australian National University ethics permit C.RE.24.02 and Queensland Environmental Protection Agency permit WITK00337502.

\section{REFERENCES}

Bell S., McCoy E. \& Mushinsky H. (1991) Habitat Structure: the Physical Arrangement of Objects in Space. Chapman \& Hall, London.

Booth C. L. (1990) Evolutionary significance of ontogenetic colour change in animals. Biol. F. Linn. Soc. 40, 12563.

Brito J. (2003) Seasonal variation in movements, home range, and habitat use by male Vipera latastei in Northern Portugal. f. Herpetol. 37, 155-60.

Brown G., Shine R. \& Madsen T. (2002) Responses of three symaptric snake species to tropical seasonality in northern Australia. F. Trop. Ecol. 18, 549-68.

Brown G. \& Weatherhead P. (1999) Female distribution affects mate searching and sexual selection in male northern water snakes (Nerodia sipedon). Behav. Ecol. Sociobiol. 47, 9-16.

Diffendorfer J., Rochester C., Fisher R. \& Brown T. (2005) Movement and space use by Coastal Rosy Boas (Lichanura trivirgata roseofusca) in coastal southern California. F. Herpetol. 39, 24-36.

Fearn S., Schwarzkopf L. \& Shine R. (2005) Giant snakes in tropical forests: a field study of the Australian scrub python, Morelia kinghorni. Wildl. Res. 32, 193-201.

Fitzgerald M., Shine R. \& Lemckert F. (2002) Spatial ecology of arboreal snakes (Hoplocephalus stephensii, Elapidae) in an eastern Australian forest. Austral Ecol. 27, 537-45.

Genstat-Committee (2003) Genstat Release 7.1. VSN International, Oxford.

Greenwood P. (1980) Mating systems, philopatry and dispersal in birds and mammals. Anim. Behav. 28, 1140-62.

Greer A. (1997) The Biology and Evolution of Australian Snakes. Surrey Beatty and Sons, Sydney.
Gregory P., Macartney J. \& Larsen K. (1987) Spatial patterns and movement. In: Snakes: Ecology and Evolutionary Biology (eds R. Seigel, J. Collins \& S. Novak) pp. 366-95. Macmillan, New York.

Harris S., Cresswell W., Forde P., Trewhella W., Woollard T. \& Wray S. (1990) Home-range analysis using radiotracking data - a review of problems and techniques particularly as applied to the study of mammals. Mamm. Rev. 20, 97-123.

Heard G., Black D. \& Robertson P. (2004) Habitat use by the inland carpet python (Morelia spilota metcalfei: Pythonidae): seasonal relationships with habitat structure and prey distribution in a rural landscape. Austral Ecol. 29, 446-60.

Hooge P., Eichenlaub W. \& Solomon E. (1999) The Animal Movement Program. USGS, Alaska Biological Survey Centre, Anchorage, USA.

Jetz W., Carbone C., Fulford J. \& Brown J. (2004) The scaling of animal space use. Science 306, 266-8.

Kays R. \& Allison A. (2001) Arboreal tropical forest vertebrates: current knowledge and research trends. Plant. Ecol. 153, $109-20$.

Kenward R., South A. \& Walls S. (2003) ranges 6 V1.2: for the Analysis of Tracking and Location Data. Online Manual. Anatrack Ltd, Wareham.

Leung L. (1999a) Ecology of Australian tropical rainforest mammals. II. The Cape York melomys, Melomys capensis (Muridae: Rodentia). Wildl. Res. 26, 307-16.

Leung L. (1999b) Ecology of Australian tropical rainforest mammals. III. The Cape York Rat, Rattus leucopus (Muridae: Rodentia). Wildl. Res. 26, 317-28.

Lillywhite H. \& Henderson R. (1993) Behavioral and functional ecology of arboreal snakes. In: Snakes: Ecology and Behavior (eds R. Seigel \& J. Collins) pp. 1-48. The Blackburn Press, Caldwell.

Macartney J., Gregory P. \& Larsen K. (1988) A tabular survey of data on movements and home ranges of snakes. $\mathcal{F}$. Herpetol. 22, 61-73.

Madsen T. (1984) Movements, home range size and habitat use of radio-tracked Grass Snakes (Natrix natrix) in Southern Sweden. Copeia 1984, 707-13.

Madsen T. \& Shine R. (1996) Seasonal migration of predators and prey - a study of pythons and rats in tropical Australia. Ecology 77, 149-56.

Magnusson K. \& Kasuya T. (1997) Mating strategies in whale populations: searching strategy vs. harem strategy. Ecol. Modell. 102, 225-42.

Neldner V. \& Clarkson J. (1995) Vegetation Survey of Cape York Peninsula. Department of Environment and Heritage, Brisbane.

O'Shea M. (1996) A Guide to the Snakes of Papua New Guinea. Independent Publishing, Port Moresby.

Parker W. \& Plummer M. (1987) Population ecology. In: Snakes: Ecology and Evolutionary Biology (eds R. Seigel, J. Collins \& S. Novak) pp. 253-301. Macmillan Publishing Co, New York.

Pearson D., Shine R. \& Williams A. (2005) Spatial ecology of a threatened python (Morelia spilota imbricata) and the effects of anthropogenic habitat change. Austral Ecol. 30, 261-74.

Rose B. (1982) Lizard home ranges: methodology and functions. F. Herpetol. 16, 253-69.

Sandell M. \& Liberg O. (1992) Roamers and stayers: a model on male mating tactics and mating systems. Am. Nat. 139, $177-89$.

Shine R. \& Fitzgerald M. (1996) Large snakes in a mosaic rural landscape: the ecology of Carpet Pythons Morelia spilota 
(Serpentes: Pythonidae) in coastal eastern Australia. Biol. Conserv. 76, 113-22.

Shine R. \& Slip D. J. (1990) Biological aspects of the adaptive radiation of Australasian pythons (Serpentes: Boidae). Herpetologica 46, 283-90.

Slip D. \& Shine R. (1988) Habitat use, movements and activity patterns of free-ranging Diamond Pythons, Morelia spilota spilota (Serpentes: Boidae): a radiotelemetric study. Aust. Wildl. Res. 15, 315-31.

Stone P. \& Baird T. (2002) Estimating lizard home range: the Rose model revisited. F. Herpetol. 36, 427-36.

Vitt L. (1987) Communities. In: Snakes: Ecology and Evolutionary Biology (eds R. Seigel, J. Collins \& J. Novak) pp. 33565. Macmillan, New York.
Webb J. \& Shine R. (1997a) A field study of spatial ecology and movements of a threatened snake species, Hoplocephalus bungaroides. Biol. Conserv. 82, 203-17.

Webb J. \& Shine R. (1997b) Out on a limb: conservation implications of tree-hollow use by a threatened snake species (Hoplocephalus bungaroides: Serpentes, Elapidae). Biol. Conserv. 81, 21-33.

Wilson D. (in press) Foraging ecology and diet of an ambush predator: the green python Morelia viridis. In: Biology of the Boas and Pythons (ed. R. Henderson). Eagle Mountain Publishing, in press.

Wilson, D., Heinsohn, R. \& Wood, J. (in press) Life history traits and colour change in the arboreal tropical python Morelia viridis. F. Zool. (Lond.), in press. 